REVISTA DE ESTUDOS EM ARTES CÊNICAS

E-ISSN 2358.6958

\title{
A voz no Treinamento Suzuki
}

Glauce Carvalho

Wânia Mara Agostini Storolli

\section{Para citar este artigo:}

CARVALHO, Glauce; STOROLLI, Wânia Mara Agostini. A voz no Treinamento Suzuki. Urdimento - Revista de Estudos em Artes Cênicas, Florianópolis, v. 3, n. 42, dez. 2021.

doi DOI: http:/dx.doi.org/10.5965/1414573103422021e0301

Este artigo passou pelo Plagiarism Detection Software | iThenticate 
Glauce Carvalho ${ }^{3}$

Wânia Mara Agostini Storolli

\title{
Resumo
}

Este artigo trata a questão da voz no treinamento e no trabalho de direção de Tadashi Suzuki, estabelecendo relações entre fundamentos da prática do diretor japonês com o pensamento sobre a voz de Adriana Cavarero. O trabalho resultou da interação entre a experiência prática com o treinamento Suzuki e a reflexão baseada nos conceitos da filósofa, especialmente ao considerar o aspecto de unicidade e a natureza relacional e corpórea da voz. Observou-se como a voz no treinamento e nos espetáculos de Suzuki é compreendida em sua dimensão universal onde, ultrapassando as amarras da semântica, o elemento vocálico pode afetar e gerar a interação com o outro - performers e público.

Palavras-chave: Treinamento Suzuki. Tadashi Suzuki. Adriana Cavarero. Voz. Teatro Contemporâneo.

\section{The voice in the Suzuki Training}

\begin{abstract}
This article explores the matter of voice in Tadashi Suzuki's training and directing work, establishing relationships between the fundamentals of the Japanese director's practice and Adriana Cavarero's thoughts on the theme. This work is the result of the interaction between the hands-on experience with Suzuki training and the reflection based on Cavarero's concepts, especially in regards to the aspect of unity and voice's relational and corporeal nature. It has been observed how the voice in Suzuki's training and in his performances ends up being understood in its universal dimension where, without the ties of semantics, the elements of voice can affect and generate interaction with one another - performers and audience.
\end{abstract}

Keywords: Suzuki training. Tadashi Suzuki. Adriana Cavarero. Voice. Contemporary Theater.

${ }^{1}$ O presente trabalho foi realizado com apoio da Coordenação de Aperfeiçoamento de Pessoal de Nível Superior - Brasil (CAPES) - Código de Financiamento 001.

${ }^{2}$ Revisão ortográfica e gramatical do artigo realizada por Márcia Plana Souza Lopes. Graduação em Letras (Faculdade de Ciências e Letras de Ribeirão Pires). Mestre em Literatura e Crítica Literária (Pontifícia Universidade Católica - PUC - SP).

${ }^{3}$ Mestranda em Artes Cênicas pelo Instituto de Artes da Universidade Estadual Paulista "Júlio de Mesquita Filho” (UNESP), bolsista CAPES. Atriz, professora e pesquisadora, graduada em História. glauce.carvalho@unesp.br

$\underline{\text { http://lattes.cnpq.br/6307803686576980 }}$ id https://orcid.org/0000-0003-1466-0926

${ }^{4}$ Pós-Doutorado em Música - Universidade de São Paulo (ECA-USP). Doutorado em Processos de Criação Musical e Mestrado em Musicologia (ECA-USP). Graduada em Música (ECA-USP). Professora da área de corpo e voz dos cursos de Artes Cênicas e professora orientadora do Programa de Pós-Graduação em Artes na Universidade Estadual Paulista "Júlio de Mesquita Filho" - (UNESP). wania.storolli@unesp.br

$(9$ http://lattes.cnpq.br/4595191742974023 (iD https://orcid.org/0000-0002-4828-9654 


\section{Resumen}

Este artículo aborda la cuestión de la voz en la formación y el trabajo de dirección de Tadashi Suzuki, estableciendo relaciones entre los fundamentos de la práctica del director japonés y el pensamiento de Adriana Cavarero sobre la voz. El trabajo resultó de la interacción entre la experiencia práctica con la formación Suzuki y la reflexión basada en los conceptos del filósofa, especialmente el aspecto de unicidad y la naturaleza relacional y corpórea de la voz. Se observó cómo la voz en los entrenamientos y actuaciones de Suzuki se entiende en su dimensión universal donde, sin los lazos de la semántica, el elemento vocal puede afectar y generar interacción con los demás - intérpretes y público.

Palabras clave: Formación Suzuki. Tadashi Suzuki. Adriana Cavarero. Voz. Teatro Contemporáneo. 


\section{Introdução}

O Treinamento Suzuki foi desenvolvido pelo encenador japonês Tadashi Suzuki, diretor da SCOT - Suzuki Company of Toga. Suzuki nasceu em 1939 na província de Shizuoka no Japão e ainda criança acompanhou a democratização e reconstrução do Japão ocupado pelos EUA em 1945. Cresceu num ambiente familiar plural, com elementos do Japão tradicional (bunraku, xintoísmo e budismo) e elementos da cultura moderna estrangeira (música e literatura clássica ocidental). Na adolescência dedicou-se à produção de poesia e leitura de clássicos ocidentais. Em 1958, junto com a graduação em Ciências Políticas e Econômicas na Universidade de Waseda, com 19 anos, entra para o grupo de teatro estudantil Waseda Jiyu Butai (Waseda Palco Livre) e em 1966 começa a desenvolver suas criações e a formar sua própria companhia de teatro, a Waseda Shogekijo (Waseda Teatro Pequeno). Ganha notoriedade investigando o teatro como um sistema artístico e experimentando suas ideias referentes ao trabalho de atriz/ator. Em 1976 muda a sede da sua companhia de Tóquio para o vilarejo de Toga, nos anos subsequentes constrói teatros, desenvolve o Treinamento Suzuki, cria encenações, promove festivais internacionais, faz parcerias e ganha reconhecimento nacional e internacional. No ano de 1984, o grupo muda de nome para SCOT - Suzuki Company of Toga. Desde então, Suzuki continua a se dedicar à criação de espetáculos, ao treinamento, à organização e participação em festivais internacionais como Theatre Olympics e SCOT Summer Season, além da companhia passar a integrar o complexo Toga Art Park, conhecido como "meca teatral". Suzuki é reconhecido internacionalmente como renovador da cena contemporânea japonesa, o "Grotowski japonês”, um dos grandes diretores de teatro do século XX, que estabelece pontes entre as formas do teatro tradicional japonês e a encenação contemporânea (Monteiro, 2009).

O Treinamento Suzuki foi criado para sua companhia e seus espetáculos, é um treinamento para atrizes/atores conhecido por ser intenso fisicamente e emocionalmente, com foco em três pilares básicos: respiração, produção de energia e equilíbrio. Segundo Suzuki, quanto mais energia somos capazes de 
produzir através da absorção de oxigênio e pelo controle do nosso centro de gravidade, mais movimentos e estabilidade somos capazes de ter: o corpo ganha força e agilidade, a voz ganha amplitude e capacidade, e a consciência do "outro" cresce. No treinamento que desenvolveu, Suzuki sistematizou e materializou suas reflexões acerca da linguagem teatral, o que chamou de disciplina de atuação. Ele redimensionou a função do espaço cênico e estabeleceu um diálogo entre as tradições japonesas e a encenação contemporânea aliando teoria e prática.

Embora seja reconhecido e mobilize atrizes e atores do mundo todo por conta do treinamento que desenvolveu, o trabalho da SCOT - Suzuki Company of Toga não se resume, unicamente, a essa técnica. Ela se expande numa filosofia que pode ser observada e sentida na forma de organização do grupo, na estrutura do Toga Art Park e seus teatros e na apresentação dos espetáculos. E mesmo tendo como foco o treinamento Suzuki, podemos destacar vários elementos específicos, entre os quais, como a voz é trabalhada.

Em Dyonisus (1990)5 , assim como em King Lear (1984) e outros espetáculos da SCOT, além de toda energia e poesia visual, a existência de atrizes e atores de diferentes nacionalidades, falando suas línguas maternas em cena, cria uma poesia sonora que transborda para além do território da semântica e leva-nos a fruir com as vozes em cena, voz/corpo compondo uma história. São atrizes e atores que realizaram o treinamento Suzuki diversas vezes e acabaram por serem convidados a fazer parte dos espetáculos ou do grupo. Mesmo tendo uma mesma formação - o treinamento - a individualidade de cada voz pode ser percebida.

Pretende-se neste artigo olhar o Treinamento Suzuki com foco na questão da voz e aspectos como individualidade, ressonância e silêncio, procurando estabelecer relações com o pensamento de Adriana Cavarero, filósofa que em Vozes Plurais: Filosofia da Expressão Vocal (2011) enfoca as relações entre voz e palavra, enquanto relação de unicidade, criticando o logocentrismo dominante na história da filosofia ocidental ao qual a voz foi submetida ao deixar em segundo plano sua natureza sonora, encarnada e singular. Tanto Suzuki quanto Cavarero,

\footnotetext{
${ }^{5}$ Segundo o site https://www.scot-suzukicompany.com/en/profile.php.
} 
trazem a questão da expressão da unicidade de cada um, da força da materialidade da voz, de sua natureza corpórea e relacional, o que nos aponta um caminho de ressonância entre prática e teoria, que pretendemos aqui delinear.

\section{Da natureza da Voz}

Cada fala carrega o traço de sua cultura - a voz traz ritmos, melodias, timbres, sonoridades que compõem uma música específica, característica. Mesmo antes do significado da palavra, sua sonoridade revela-nos algo sobre sua essência e desperta nossa expectativa para os sons que virão em seguida. Ao adentrar em outra cultura, em uma língua desconhecida, a semântica foge-nos. Temos então a percepção mais precisa de que, primordialmente, a voz é som, e em sua musicalidade nossa expectativa é quebrada pela cadência diferente através da qual ocorre a comunicação. A quebra do esperado torna-nos mais atentos, não somente ao ritmo das palavras, mas às pausas e aos espaços "entre" existentes. Eles nos dizem algo nessa partitura musical que faz parte da composição, da leitura do todo, que é relacionado ao timbre, ao volume, à intensidade, ao tom e às pausas.

Em Estética da criação verbal (2003) Mikhail Bakhtin observa como a cultura alheia se manifesta completa e profundamente aos olhos de outra cultura, de como abarcam as questões que não havíamos nos colocado e como descobrimos novos aspectos em nossa própria cultura por esse encontro (Bakhtin, 2003). Através da voz, a cultura alheia se manifesta aos nossos ouvidos. Em contato com uma língua desconhecida podemos perceber as expressões sonoras, a respiração e pausas de uma fala, e entendemos que estas também têm ressonância e criam um halo de comunicação, proporcionando o entendimento do protagonismo da voz, trazendo a percepção de que estamos lidando com um entendimento universal: todos sabemos da respiração, do grito, do riso e do silêncio. 


\title{
A voz no Treinamento Suzuki
}

Desde as artes tradicionais do Japão, canto e dança sempre estiveram integradas e num lugar de base. O teatro noh nasce das apresentações cômicas populares dengaku e saragaku. O dengaku constituía-se de canções e danças apresentadas pelos agricultores e sacerdotes e o saragaku era uma espécie de farsa. (Kusano,1984, p.15). A palavra kabuki é por vezes traduzida como "a arte de cantar e dançar" e o significado individual de cada ideograma é canto (ka) (歌), dança (bu) (舞) e habilidade (ki) (伎) (Bertold, 2004, p.91).

O teatro de Tadashi Suzuki é visto pelo Ocidente como um hibridismo da arte tradicional com a arte contemporânea e a forma como o treinamento foi desenvolvido é baseado nas formas e princípios do noh e kabuki, definindo o corpo do ator e produzindo uma vivacidade através das disciplinas de atuação (Monteiro, 2009).

Antes de analisar esse trabalho é preciso entender, primeiramente, a filosofia da SCOT (Suzuki Company of Toga) como um todo, uma prática integralizada, que tem reflexo em cada detalhe, seja no treinamento, seja nos espetáculos ou na organização dos festivais internacionais. Uma forma de fazer arte distinta, provinda de outra cultura, que trabalha de forma integral, indissociável do dia a dia.

\begin{abstract}
O treinamento é um elemento característico e indissociável do modo de vida cultivado em Toga. Todos os dias são dias de estar na sala de trabalho e as demais atividades cotidianas se dividem por acontecerem antes ou depois do treinamento. Os/As integrantes da SCOT compartilham diferentes tarefas, como cuidar da alimentação dos/das visitantes, organizar os espaços de trabalho, executar tarefas de produção executiva (ao telefone, no computador etc.), fazer a manutenção das áreas comuns do Toga Art Park como os diversos teatros, áreas verdes e hospedaria (Lodi, 2015, p.43 ).
\end{abstract}

O Treinamento Suzuki acontece na sede da SCOT, localizada no Toga Art Park, no vilarejo de Togamura. Esse vilarejo fica a 2 horas e meia de Tóquio, nas montanhas da província de Toyama e tem aproximadamente 700 habitantes. 0 acesso é via carro ou por ônibus em horários bem restritos. Toga Art Park é uma 
área verde composta de alojamentos, teatros, sala de ensaio, escritório e refeitório, com toda estrutura envolta pela natureza que circunda os teatros e as residências das atrizes e dos atores da SCOT.

O treinamento é oferecido uma vez ao ano para artistas e alunos de teatro, uma verdadeira imersão com duração de 15 dias, com 6 horas de trabalho físico, divididos em manhã e tarde, mais 2 a 4 horas de vídeos à noite, com bate papo e acompanhamento dos ensaios da SCOT.

Nos primeiros dias de treinamento são passadas noções físicas, práticas sobre a gramática dos pés, energia, respiração e equilíbrio. O treinamento iniciase, pontualmente, como um ritual, sempre de forma prática com um exercício chamado stomping (golpes), que consiste em bater os pés no chão, buscando manter uma postura, respiração e energia durante mais ou menos 4 minutos ao som de uma música ritmada semelhante a uma marcha militar. No livro Culture is the Body (2015) Suzuki relata a origem desse exercício nas artes tradicionais, que desperta o corpo, conecta-o ao espaço, desperta a energia animal para que se sinta e se afete pelo ambiente e pelo outro.

Durante a semana, pouco a pouco são introduzidas todas as disciplinas de atuação denominadas como basic exercises (exercícios básicos), slow ten (caminhada lenta), sitting and standing statues (posições de estátuas sentada e pé) e walks (caminhadas).

Ao final da primeira semana de treinamento começam as vocalizações junto às disciplinas de atuação basic exercises e sitting and standing statues. Esses exercícios vão se somando e são repetidos a cada encontro. Em todo treinamento somos incentivados a estar presentes, sentir e entender com o corpo. Se um participante precisa de uma maior indicação para executar uma determinada disciplina de atuação, um integrante da SCOT posiciona-se ao seu lado e faz o exercício junto com ele até que seu corpo perceba, organicamente, a melhor forma de realizá-lo, pois todo o treinamento é focado na prática e a reflexão fica para fora da sala de ensaio, após o horário de trabalho.

Na segunda semana, já com o corpo desperto, familiarizados(as) com as disciplinas de atuação e mergulhados(as) na filosofia do grupo, é passado um 
texto às/aos participantes para que seja decorado.

O texto abaixo foi dado às/aos participantes do Treinamento Suzuki de 2019:

Kore made jinru wa sensō ni tsugu sensō de isogashiku (respirar)

Ensei dano shin'nyu dano gaisen dano de, sono zen sonzai o mitashite kimashita ga (respirar)

Ima ya sō yu jidai wa owari o tsugete, ato ni wa jitsu ni okina kudō ga aite iru.

O Treinamento Suzuki de 2019 aconteceu de 21 de julho a 4 de agosto e foi composto de 39 participantes de 33 nacionalidades diferentes. O texto estava em japonês e nenhum participante tinha essa nacionalidade ou falava fluentemente a língua. Foi passada a indicação de que se tratava de um trecho do texto das Três irmãs de Tchekhov. A instrução foi a de não buscar a tradução, a única pontuação dada era onde deveríamos respirar.

O objetivo é falar o texto somente depois de ter o corpo preparado, desperto pelo treinamento da primeira semana, apoiando-se na noção de que não há de fato cisão entre corpo e voz e que, portanto, as alterações físicas reverberam nas formas que a voz assume. Segundo Suzuki, se você não pode ser visto, não vai ser ouvido. A voz, então, desenha o texto, não pelo entendimento racional, mas física, energética e musicalmente. A voz materializa sonoramente o texto por meio de dinâmicas que conjugam ação, respiração e energia. Com toda essa energia gerada, ao falar o texto, a qualidade da voz é outra, potente, precisa. Sem que seja ensaiada, a voz sai organicamente, forte e intensa. Como afirma Suzuki:

O teatro começa quando uma pessoa projeta sua voz no espaço para contar uma história - seja através de um grande drama, poesia ou mesmo improvisação - e aqueles que assistem encontram valor na energia / ação dessa pessoa e são seduzidos por ela. É quando o ato de contar histórias se torna uma espécie de artimanha, o que eu gosto de chamar de "persuasão". Essa persuasão não ocorre através das interpretações intelectuais de um texto, mas sim quando o próprio ato de falar se torna o drama - quando a mudança que acontece no interior do locutor se revela. Essa transformação é o que nos referimos como atuação. Mais especificamente, o poder de persuasão surge quando o uso atraente de linguagem e espaço, ação e energia por parte de um ator geram uma consciência visceral extraordinária e inconstante entre ele e o público. [...] É por isso que a fonte do carisma de um ator 
verdadeiramente grande não é encontrada no texto, mas sim na fala subconscientemente dirigida do texto, que transfigura o ator em seu maior potencial (Suzuki, 2015, p.5). ${ }^{6}$

Segundo Anne Bogart, diretora de teatro americana e diretora artística da SITI Company que fundou com Tadashi Suzuki em 1992, em entrevista concedida a Fabiano Lodi ${ }^{7}$ no projeto de lives Internacionais da Leneus produtora, realizado em parceria com as Oficinas Culturais do Estado de São Paulo no dia 19 de outubro de $2020^{8}$, o Treinamento Suzuki proporciona às atrizes/ aos atores uma consciência corporal e vocal. Primeiro o treinamento faz com que o corpo fique mais responsivo e reflexivo, algo inconsciente, para que alcance um relaxamento, uma abertura de determinadas partes do seu corpo que fazem com que se consiga alcançar uma diferenciação na voz, uma cor vocal e mudança de timbre. (Bogart, 2020). Voz é corpo e o treinamento Suzuki é conduzido a partir desta perspectiva.

A noção de que a mudança interna, que ocorre na atriz/no ator e manifesta no drama, como observa Suzuki, é revelada pelo corpo e pela fala, ou seja, pelo corpo e pela voz que se expande para o espaço, encontra ressonância no conceito de unicidade apresentado por Adriana Cavarero. Para a filósofa, "a voz é o equivalente daquilo que a pessoa única possui de mais escondido e verdadeiro" (Cavarero, 2011, p.18). Essa diversidade repousa na singularidade de cada corpo. Enquanto, afirma Cavarero, a combinação das palavras não é “indício suficiente da unicidade de quem fala. A voz de quem fala é, pelo contrário, sempre diversa de todas as outras vozes [...]" (Cavarero, 2011, p.18). Essa voz que ressoa e que é capaz de instaurar uma atmosfera diversa da cotidiana, trazendo a presença

\footnotetext{
${ }^{6}$ Theatre begins when a person projects his or her voice in space to tell a story-be it through great drama, poetry or even improvisation - and those watching find value in that person's energy/action and are seduced by it. This is when the act of storytelling becomes a kind of deceit, what I like to call "cozening." This cozening does not occur through the intellectual interpretation of a text, but rather when the act of speaking itself becomes the drama-when the change that happens inside the speaker reveals itself. This transformation is what we refer to as acting. More specifically, the power to cozen emerges when an actor's appealing use of language and energy, generates an extraordinary, constantly shifting visceral awareness between him or herself and the audience. [...]. This is why the source of a truly great actor's charisma is not found in the text, but rather in the subconsciously driven speaking of the text, which transfigures the actor into his or her greatest potential self. (Tradução nossa)
}

${ }^{7}$ Fabiano Lodi é diretor teatral e mestre em Teatro pela UNESP. Desenvolve pesquisas em arte investigando a articulação de técnicas de treinamento na prática de direção. Suas experiências incluem participações em programas internacionais de formação artística, como os realizados nos Estados Unidos e Japão.

${ }^{8}$ Disponível em: www.youtube.com/watch?v=fheLpvUoKpg\&t=1815s 
daquele que fala e revelando uma verdade, ainda que fictícia como no teatro, é um fato que repousa no elemento vocálico. Diferentemente de verdades postas pela razão, comenta Cavarero, a "verdade do vocálico", longe de ser abstrata, proclama a unicidade de quem fala.

Há algo então essencial na voz, no ato da fala, que mesmo partindo de um texto, permite a transfiguração da atriz/do ator e o surgimento desta qualidade nomeada como "presença”, capaz de integrar o público em uma vivência intensa e contagiante. A fala traz esse algo primordial da voz, anterior a construção das palavras, onde o vocálico permite o surgimento da unicidade de cada voz. Assim, entende-se como nos espetáculos da SCOT diversas línguas podem estar presentes. Mesmo sem o público ter a compreensão semântica do texto, este é revelado pelas vozes.

A voz nos espetáculos da SCOT tem, portanto, uma presença forte seja em qual língua for. Em diversos espetáculos, Suzuki trabalha com atrizes e atores de diferentes nacionalidades, que falam sua língua mãe, e através de suas falas trazem os textos clássicos como As bacantes de Eurípides ou Rei Lear de W. Shakespeare, criando uma camada a mais de representação, um entendimento além da semântica, um dos motivos que faz seus espetáculos tão hipnotizantes.

\section{Ressonâncias entre Suzuki e Cavarero}

Cavarero traz a questão da unicidade da voz, observando que "o âmbito da voz é constitutivamente mais amplo que o da palavra" (Cavarero, 2011, p.28), conceito perceptível na prática de Suzuki. A filósofa trabalha desde a mais crua ideia de que diante da voz as palavras soam como ruídos se não estão unificadas a ela, que a voz carrega sentido em si e não é somente um meio, que desvinculada da voz a palavra perde sua potência e sentido (Cavarero, 2011). Estabelecer conexões entre o pensamento de Cavarero e o trabalho prático e filosófico de Suzuki, assim como ao pensamento oriental vivido no dia a dia, gera um campo de pesquisa fértil a ser pesquisado e experimentado.

Considerando que os sons são especialmente capazes de gerar 
determinadas atmosferas, a percepção da voz em sua materialidade sonora conduz à percepção de que há possíveis atmosferas geradas pela voz. São atmosferas específicas e características de cada voz, pois "distintamente das formas de expressão verbal, a voz é altamente individual, de tal forma que a atmosfera por ela determinada, pode ser descrita e reconhecida como própria" (Böhme, 2009, p.30). A percepção desta atmosfera gerada pela voz ocorre não apenas pela audição, mas também através de uma participação afetiva, por uma espécie de contágio, como se fossemos envolvidos pela atmosfera, pelo caráter emprestado ao espaço pela voz, algo que ocorre principalmente através da ressonância. Portanto, atmosfera e ressonância se relacionam intimamente com os espaços.

Essa instauração de um espaço sonoro através das vozes e ressonâncias, falas e silêncios que geram a possibilidade de afetar o outro é também perceptível na prática e nos espetáculos de Suzuki, algo que possibilita a inclusão concomitante de línguas diversas, de pausas cheias de presença.

Ao olhar para silêncios como potência e ressonância, podemos ainda relacionar o pensamento de Adriana Cavarero com o do filósofo japonês Masakatsu Fujita, para quem a importância está na comunicação vocal, física, energética e não na semântica. O pensamento de Fugita também reverbera na forma como Suzuki trabalha em seus espetáculos a ressonância das palavras, a pausa cheia de energia e o silêncio prenhe de significado. Segundo Fujita, esses silêncios produzem um espaçamento entre as coisas e entre os acontecimentos. Os silêncios se apresentam como um importante intervalo que condensa a melodia ou a interpretação que nos precedem. Não são meros espaços vazios, mas lugares de ressonância, temporalidade e espacialidade de tensão que mobiliza os corpos. A parede entre espectadores e atrizes/atores é atravessada e eles mergulham um no outro por meio da materialidade da voz, dos silêncios, da ressonância no espaço, dessa atmosfera de afetos num mesmo espaço (Avancini; Hashimoto Cordaro; Okano, 2021).

Quando se diz: "Ah, como é lindo!", existe um espaçamento temporal entre "Ah" e "como é lindo!". Em vez de palavras, esse intervalo acolhe a ressonância do sentimento presente no âmago de "Ah". A literatura 
japonesa deu uma grande importância a essa "sonoridade silenciosa" criada por tal ressonância. Isso ocorre porque essa sonoridade silenciosa faz justamente surgir uma simpatia entre o locutor e o interlocutor, ou entre o escritor e o leitor (Avancini; Hashimoto Cordaro; Okano, 2021, p.177).

Podemos chamar esses espaços de espaços de ressonância, espaços sonoros e silenciosos, que possibilitam comunicação e diluem fronteiras. As vozes soam, geram ressonâncias, primeiro em nós mesmos e depois afetam o outro como gesto físico. Tanto no treinamento quanto nos espetáculos, Suzuki trabalha com a materialidade, com respiração, equilíbrio, energia afetando atrizes/atores e público. Suzuki trabalha com voz e silêncio, gestos e pausa, experimentando as sensações que cada elemento proporciona.

\section{O silêncio no entre-espaço das palavras}

Dos questionamentos mais simples, como por exemplo, "Grito é fala?", somos levados a entender que estamos repletos de gestos sonoros e a tomar ciência da sonoridade e de que existem sons silenciosos e vozes sem som. 0 teatro de Tadashi Suzuki experimenta em cena, nos treinamentos e nos ensaios esses elementos e de forma prática testa sua teoria.

Segue-se que o principal objetivo do diretor deve ser estabelecer um lugar onde ele possa rapidamente fazer esse tipo de conexão forte entre texto escrito, ator e público. Ele não deve se sentir pressionado a explicar completamente o texto para seus atores, obrigando-os, por sua vez, a educar o público, ou visualizar cenas para eles na maneira de realismo, ou seja, "essas palavras devem ser ditas como se estivessem na sala russa" ou "no restaurante americano" etc. Embora eu não negue que tais técnicas possam ajudar os atores a criar uma espécie de persuasão, elas não são essenciais para o trabalho criativo do diretor. [...]. Em alguns casos excepcionais, o ator pode não falar nada, mas apenas se movimentar. Nesses momentos, para evitar que o teatro se abstraia em dança, o diretor deve ajudar o público a descobrir como o silêncio pode ser ainda mais eloquente do que a fala. É assim que um diretor prova seu talento (Suzuki, 2015, p.6). ${ }^{9}$

${ }^{9}$ It follows that the director's primary objective must be to establish a place where he can quickly make this kind of strong connection between written text, actor and audience. He should not feel pressured to completely explain the text for his actors, obligating them in turn to educate the audience, or visualize scenes for them in the manner of realism, i.e., "these words are to be said as if in a Russian living room," or "in an American diner," etc. While I don't deny that such techniques can help actors create a kind of cozening, they are not essential to the director's creative work. [...]. In some exceptional cases, the actor may not speak at all, but only move. At such times, to prevent theatre from abstracting into dance, the 
Esse silêncio, essa pausa, podemos perceber no teatro japonês de forma dilatada, na atuação dos atores nos teatros tradicionais noh, kabuki, bunraku, nas danças e também no teatro do diretor Tadashi Suzuki.

Nos espetáculos contemporâneos de Tadashi Suzuki, observamos esse tempo dilatado, prenhe de possibilidades, silêncios, pausas, vazios, com atrizes/atores de nacionalidades distintas no palco, com suas línguas mães se comunicando de forma orgânica suas vozes com velocidade, precisão e volume, vozes reverberando em seus corpos, impactando sua relação com o público, reflexo da crença de Suzuki de que o primordial no teatro é a presença da atriz/do ator, seus corpos, suas vozes, silêncios e pausas da cena, no desenvolver do trabalho que se dissocia de um teatro submisso ao texto:

A expressão no teatro não consiste apenas em movimentos de dança do corpo. O que faz o teatro teatral envolve todas as variações do corpo ao falar. Eu tentei examinar de perto todas as posturas usadas na vida cotidiana de uma pessoa, particularmente quando falamos. As palavras que falamos realmente influenciam nossa situação física, mas há um número limitado de situações básicas que podem ser observadas em um número finito de combinações. O primeiro dever do ator contemporâneo é objetivar essas situações corporais, determinar o contexto emocional que as palavras criarão sob cada conjunto de circunstâncias e, então, ter consciência dessas relações (Suzuki, 2015, p.75). ${ }^{10}$

Suzuki trabalha voz e corpo integrados, entendendo que o corpo se afeta com a fala e que a fala é afetada pelas alterações do corpo. De forma metodológica analisa essa relação, desmembrando em disciplinas de atuação. Através do treinamento faz com que o corpo da atriz/do ator esteja presente nessa relação de forma orgânica e consciente do que essa relação é capaz.

director must help the audience discover how silence can be even more eloquent than speech. This is how a director proves his or her talent. (Tradução nossa)

${ }^{10}$ Expression in the theatre does not merely consist of dance-like motions of the body. What makes the theatre theatrical involves all the variations of the body when speaking. I have attempted to examine closely all the postures used in a person's daily life, particularly when speaking. The words that we speak truly influence our physical situation, but there are a limited number of basic situations that can be observed in a finite number of combinations. The contemporary actor's first duty is to objectify those bodily situations, determine the emotional context that words will create under each set of circumstances, and then be conscious of these relationships. (Tradução nossa) 


\section{Considerações Finais}

A interação entre a experiência prática com o treinamento Suzuki e a reflexão baseada nos conceitos da filósofa Adriana Cavarero fez ficar palpável o entendimento da voz e sua ressonância, embora ainda exista um universo a pesquisar acerca da unicidade, da natureza relacional e corpórea da voz em relação ao trabalho desenvolvido por Suzuki.

Os lugares de ressonância trazem a compreensão da dimensão sonora da voz e também a noção de que a pausa integra a voz, assim como o silêncio faz parte do som. Suzuki trabalha com a voz na sua forma orgânica, com silêncio e som e busca que atrizes e atores se expressem com seus corpos e vozes, ele encontra uma confluência teórica e prática, buscando na sua própria tradição, formulando suas bases e criando pontes entre o contemporâneo e o tradicional.

Cavarero traz a afirmação de que a voz não engana, suas inflexões e seus silêncios também falam algo de quem a emite, permitindo conhecer suas intenções e identificar o sentido de seu discurso, distanciando-nos das amarras da semântica e aproximando-nos do elemento vocálico. Suzuki e Cavarero entendem como a respiração, a ressonância, os silêncios e as pausas são capazes de afetar e gerar a interação com o outro, tornando possível misturar idiomas, respeitando a unicidade da voz e sua verdade. Esse artigo acontece como ponto de partida de um caminho possível de ser trilhado entre artista e filósofa.

\section{Referências}

AVANCINI, Atílio; HASHIMOTO CORDARO, Madalena; OKANO, Michiko (Org.). Conceitos Estéticos: do transtemporal ao espacial na arte japonesa. Guarulhos: EFLCH-UNIFESP, 2021.

BAKHTIN, Mikhail. Estética da criação verbal. 4. ed. São Paulo: Martins Fontes, 2003.

BERTOLD, Margot. História Mundial do Teatro. São Paulo: Perspectiva, 2001.

BOGART, ANNE 1 vídeo (43.28). Live Internacional: Fabiano Lodi conversa com 
Anne Bogart. Publicado pelo canal Leneus Produtora de Arte, 2020. Disponível em: <https://www.youtube.com/watch?v=fheLpvUoKpg\&t=1815s >. Acesso em: 29 out. 2020.

BÖHME, Gernot. Die Stimme im Leiblichen Raum. In: KOLESCH, Doris. PINTO, Vito. SCHRÖDL, Jenny (Hg.). Stimm-Welten: Philosophische, medientheoretische und ästhetische Perspektiven. Bielefeld: Transcript, 2009, p.23-32.

CAVARERO, Adriana. Vozes Plurais: Filosofia da expressão vocal. Belo Horizonte: UFMG, 2011.

KUSANO, Darci Yasuko. O que é Teatro Nô. São Paulo: Brasiliense,1984.

LODI, Fabiano. A prática do treinamento como atividade sagrada na SCOT: Tadashi Suzuki e o teatro como modo de vida. Urdimento - Revista de Estudos em Artes Cênicas, Florianópolis, v. 2, n. 25, p.34-48, 2015.

MONTEIRO, Juliana. Quando a Técnica transborda em poesia: Tadashi Suzuki e suas disciplinas de atuação. São Paulo, 2009. Dissertação (Mestrado) - ECA Escola Comunicação e Arte - Universidade de São Paulo, São Paulo, 2009.

SUZUKI, Tadashi. Culture is the Body: the Theatre Writings of Tadashi Suzuki. New York: TCG, 2015.

SUZUKI TADASHI / SUZUKI COMPANY OF TOGA. Japão. Disponível em: https://www.scot-suzukicompany.com/en/profile.php. Acesso em: 15 ago. 2021.

Recebido em: 30/08/2021

Aprovado em: 23/11/2021 